\title{
A INFLUÊNCIA DO FIGURINO NA DANÇA: ROUPA, MOVIMENTO, ESPAÇO E CORPOREIDADE
}

Profa. Dra. Marilia Vieira Soares e Profa. Ms. Maria Alice Ximenes ${ }^{1}$

O presente trabalho é resultado de uma montagem cênica - As Troianas versão para dança-teatro, realizada pelo Grupo AR Cênico. Os laboratórios de construção de personagens foram comuns à Direção e a concepção do Figurino, tendo esta integração influenciado profundamente a construção coreográfica.

A escolha de As Troianas, texto original de Eurípides para trabalho do Grupo Ar Cênico, foi um processo longo e demorado de análise de texto e contextualização na época atual. Datado de um período final de auge do teatro/dramaturgia grega, a grande inovação do texto foi sua descontinuidade e ruptura com a regra de Tempo-Lugar-Ação presente na cena grega clássica, pela inversão do tema: a guerra do ponto de vista dos vencidos.

Nesse período, a guerra para os gregos havia se tornado um estado comum, que Eurípides critica enfaticamente neste texto. "As Troianas" é uma crítica pungente à Guerra. A peça é apenas uma sucessão de assuntos penosos de fim de guerra: nela não há herói, ação contínua ou tempo preciso. É tudo feito para causar a catarse a respeito da Guerra, onde a mensagem é: os vencedores terão pior sorte que os vencidos. É neste sentido que o grupo pensa a peça: uma crítica à Guerra, onde não há vencedores, só vencidos. A atualidade do tema e a modernidade do texto foram o motivo maior da escolha.

Estamos em guerra, mas que guerra é essa? A partir da escolha do texto foi feita a chamada entre os alunos dos cursos de teatro e dança da Unicamp, que resultou na encenação apresentada. Durante o percurso dos laboratórios com a utilização da Técnica Energética (TE) fiz o convite á doutoranda Maria Alice Ximenes para a concepção do figurino. Sobre a Técnica Energética e o Método Energético:Tema da tese de doutorado defendida na FE-Unicamp em 2000, este trabalho é sistematização de um

Profa. Dra. Marilia Vieira Soares: Doutora pelo Instituto de Educação da UNICAMP, docente no Departamento de Artes Corporais e Programa de Pós Graduação em Artes na UNICAMP.

Profa. Ms. Maria Alice Ximenes: Doutoranda pelo Instituto de Artes da UNICAMP, docente nas Faculdades SENAC SP, UNISAL - Americana e METROCAMP - Campinas. 
treinamento corporal para o intérprete a partir do pressupostos básicos do Método Energético de Direção Teatral desenvolvido pelo Prof. Dr. Miroel Silveira da ECA-USP.

Trata-se da utilização dos centros energéticos do corpo humano os chakras - no desempenho do ator/dançarino.

Utiliza-se de dois sub-chakras: pés e joelhos, e sete chakras principais: Básico, Plexo-Solar, Sub-Plexo Solar, Cardíaco, Laríngeo, Terceira Visão e Coronário.

Para tanto foram estudados os pontos do corpo e as funções de cada um para relacioná-los com as características dos personagens cênicos.

\section{Análise das personagens em As Troianas}

Após o fim da sangrenta guerra entre gregos e troianos, encontra-se derrotada; seus homens foram mortos e as mulheres escravizadas, inclusive as três representantes da nobreza: Hécuba, a rainhamãe; sua filha Cassandra - Sacerdotisa de Apolo, que prediz o futuro nefasto dos gregos, e sua nora Andrômaca, cujo filho Astianax - único homem sobrevivente - é assassinado. O rapto de Helena, esposa de Menelau, Rei de Esparta, por Paris - o príncipe de Tróia, é o motivo desta longa batalha, vencida pelos gregos através do cavalo de Tróia. Taltíbio, o revoltado arauto de Agamêmnon, treinou a vida toda para ser um grande guerreiro e acaba tendo que executar tarefas tão como prender mulheres e executar o bebê Astianax, o que lhe provocam pesadelos.

Menelau vem pessoalmente buscar Helena, mas o reecontro não é tranqüilo: Hécuba adverte-o dos perigos vindouros e exige a morte de Helena, mas termina lamentando sua sorte e sepultando o neto morto antes de sua partida como escrava de Ulisses...

Utilizamos a Técnica Energética associada aos princípios da medicina oriental, que coincide com a análise junguiana das personalidades, mas vai a fundo relacionado os arquétipos com tendências fisiológicas.

Hécuba é uma senhora bem idosa, avó de muitos netos. Seu biotipo é o Shao-yang, ou seja, tem como prioridade o pensamento, a razão. Seu chakra de biótipo é o Laríngeo, mas com personagem da velha senhora, é o Coronário. Trata-se da personagem mais complexa neste texto por ter o corpo do Coronário, e o comportamento do Laríngeo. Sua ira que é uma prerrogativa do chakra Laríngeo invertido, está explícita nitidamente no texto. 
Cassandra é a sacerdotiza de Apolo, seu biotipo é Tai-Yang, ou seja, predomina a Intuição; seu chakra é a Terceira Visão, fonte das atitudes visonárias. Devido a maldição de Apolo, ninguém entende as previsões dela. Andrômaca é a senhora, esposa e mãe exemplar. Viúva de Heitor, o Príncipe de Tróia morto na guerra, resta-lhe nas mãos o filho Astianax, que deveria tornar-se um guerreiro e vingar a destruição da cidade, mas Agamenon teme esse fim e ordena a Taltíbio que o execute. Seu biotipo é o Shao-Yin, ou seja, predomina a Emoção; seu chakra é o Cardíaco.

Helena, esposa de Menelau raptada por Paris, tenta através de bela argumentação convencer o esposo de sua inocência, tentando seduzi-lo novamente. Seu biotipo é Tai-Yin, ou seja, predomina a Percepção e os sentidos. Seu chakra é o Básico. A cena termina dúbia como o texto, com Menelau conduzindo Helena para seu navio e para outro, como desejava Hécuba temerosa de um possível perdão.

Menelau permanece com atitude de vitória; seu chakra é Plexo Solar, o centro do poder, da força física com pinceladas de Cardíaco no seu reencontro com Helena.

Taltíbio é o mensageiro de Agamenon, intermediário entre as mulheres vencidas e os gregos. É um guerreiro, mas muito mais sensível que os reis, compadece-se do sofrimento das mulheres, sendo uma personagem dinâmica dentro do texto e dentro da montagem. Inicia com postura forte e decidida e termina dominado pelo sofrimento das vítimas. Seu chakra é o Plexo-Solar, mas vai cada vez mais para o Cardíaco, terminando arrasado com o funeral de Astianax feito pela avó que se despede de Tróia.

O convite para criar o figurino para peça "As Troianas", adaptado do texto original de Eurípedes; dirigido pela Profa. Dra. Marilia Vieira Soares, foi um desafio para o ritmo estabelecido do processo criativo do desenvolvimento de figurinos. Ocorre que a encomenda das vestimentas para seus personagens, contava com uma exigência: figurinos não datados e sim conceituais.

Normalmente o processo de criação e desenvolvimento de figurinos segue o roteiro de que, se conhece o histórico da peça, na seqüência se obtém informações sobre as características dos personagens e, por fim se assiste aos ensaios para desenhar e pesquisar a matéria prima utilizada, cores e design das peças.

Mas nessa experiência esse estabelecido e organizado roteiro é modificado, a presença do figurinista como membro participativo dos laboratórios altera o procedimento comum. Esse processo criativo 
contrário, originou experimentos que possibilitaram invenções na coreografia de cada quadro. Durante esses laboratórios todo o trabalho era realizado junto, não havia um trabalho isolado; o nascimento de cada figurino tinha que ser carregado da essência do movimento, da emoção juntando-se à da beleza plástica e que dependendo da forma ou tecido sobre o corpo, os bailarinos tinham uma proposta de desenhar juntos o figurino com seus movimentos.

Mediante a solicitação da diretora Marilia, para que os figurinos possuíssem uma sintonia com suas Técnicas Energética (leia-se Fundamentos Corporais de Expressão e Movimento UNICAMP, 2003) inicia-se uma jornada de experimentos que romperam os paradigmas usuais do desenvolvimento em detrimento dos procedimentos comuns no que diz respeito à criação e construção dos figurinos.

No primeiro laboratório levei um figurino em forma de anel de Moébius, cheio de aberturas (buracos na sua extensão) e os personagens Menelau e Helena criaram movimentos que remetem a forma do anel e propõe movimentos e gestos circulares e entrelaçados como um elo, que advém do figurino que veste os dois personagens numa única peça.

Todavia, esse figurino irá sofrer modificações, pois ele apenas foi um piloto para originar a forma ideal e trazer criatividade aos bailarinos para desenvolverem a cena sensual em que Helena dança com véus em movimentos arredondados tentando quebrar a rigidez de Menelau. É interessante perceber o quanto os bailarinos se envolveram com as peças de laboratório permitindo ao intérprete criador (diretora- bailarinos figurinista) uma sensação nova; de estudo do movimento à partir do objeto experiencial interagindo junto (figurinos).

Naturalmente a forma do objeto no espaço se modifica com o corpo, e conseqüentemente o corpo se modifica no espaço com o objeto vestível, e não há uma real separação entre espaço, corpo movimento e figurino; todos fazem parte de uma mesma energia.

Soares defende estados energéticos do corpo como fonte de criatividade, relaxamento e abertura para novos insights; em sintonia à técnica de François Delsarte (1811-1871), a diretora trabalha as leis do movimento, norteados pela direção, pelo gesto, pelo foco e pela harmonia dinâmica sensorial; além dos chakras corporais que ajudaram a definir as formas dos figurinos e as cores. 
Através da exploração dos planos baixo, médio e alto, gestos rígidos e simétricos, ou moles e redondos, o desenho do figurino passa a se entender num estado de motricidade.

O figurino do guerreiro Taltíbio, foi um outro estágio interessante, apesar do personagem em sua insatisfação de agir contra os princípios que fora treinado, ele desenha no espaço movimentos de uma conduta de obediência e transtorno, que desencadeará em delírios; para tanto, seu figurino será agressivo como sua emoção, mas que lhe oferecerá liberdade, pois há um longo quadro em que suas performances exigem uma roupa que não lhe faça perder os abruptos movimentos bruscos. Uma camiseta de malha recoberta por zíper trator será sua couraça e uma calça em formato de triângulo lhe permitirá sisudez e conforto ao mesmo tempo.

Menelau precisava de uma capa autoritária que lhe revelasse poder e que produzisse um balanço que evidenciasse suas performances de braços e mãos. Desenhamos muitas capas, que foram em forma de peça piloto ou experimental, usadas nos laboratórios, muitas dessas capas foram desastrosas, que amarravam a coreografia do personagem, até que um semi círculo com pontas longas na parte frontal sugeriram a imponência de que Menelau necessitava. A capa em forma de pelerine lhe conferiu uma movimentação vermelha imponente. Cassandra, a sacerdotisa, ganhou muitas vestes em amarelos e laranjas misturados à adereços dourados, sua roupa foi toda pensada em se desmontar particularmente mais que a dos outros personagens; pois esta se renderia à condição de escrava, seus giros pareciam configurar chamas de fogo no espaço.

Andrômaca, a jovem mãe, tinha movimentos muito maternais de desespero em proteger o filho bebê, todo seu ensaio com o anel de Moébius, desenhou uma imagem santificada, quase uma madona, talvez por explorar a extensão do tecido até a cabeça, trazia uma imagem afetiva de mãe virtuosa tendo o manto santo sobre a fronte. Seu figurino acabou sendo o entrelaçamento de muitos Moébius, que firmaram a idéia de desejo de esconder seu filho dentro dela mesmo.

A forma se desenha no espaço, ela não tem um desenho, já dizia Degas; prova disso foi a experiência de criar o figurino da personagem Hécuba. No laboratório em que analisávamos os tecidos recebidos de doação, encontramos um veludo de caimento molengo e pesado com efeito furta cor, que variava entre cinzentos prateados e um verde petróleo. Num breve movimento desse tecido em volta do meu corpo, eu e Marilia tivemos a certeza que aquela impressão senhoril da velha sábia, havia se registrado. 
Rapidamente desenhei o figurino de Hécuba, onde um grande retângulo com apenas duas costuras laterais iriam determinar uma veste que conferiam a forma que Camila Soares (bailarina) necessitaria para suas ações em palco. O laboratório em que fizemos o manto longo do bebê que continha um tecido escondido vermelho em seu interior, foi de grande impacto metafórico para sinalizar a morte daquele que seria o grande herdeiro de Tróia.

A idéia de desmontar os figurinos em cena fazia parte da direção coregráfica. Isso desencadeou em desenhos de figurinos fáceis de vestir e retirar, onde internamente todos os corpos possuíam uma malha marrom de forma simples e leve que não alterava a forma do figurino principal.

Semiótica-mente tivemos nesse processo todo, estágios em que o figurino significante em sua forma materializada junto ao corpo e ao movimento no espaço; cumpriu sua mensagem de significar para diferentes interpretações. Romper contextualidades estabelecidas e deixarmos os saltos quânticos nos possibilitarem aberturas para novas realidades possibilitou-nos essa grande experiência.

“.... a estática é a vida do gesto enquanto que a semiótica é o espírito. A semiótica determina o valor dos tipos, das formas que afetam os agentes da expressão. A semiótica é análise da forma orgânica e o estudo do sentimento que determina formas..." (BARIL, 1977:12)

\section{Bibliografia}

BARIL, Jacques. A Dança Moderna de Isadora à Twila Tharp. Paris: Vigot Édictions, 1977.

ROPA, Eugenia Cassini. La danza e lágitprop. I teatri-non-teatrali nella cultura tedesca del primo Novecento. Bologna: Il Mulino, 1988.

SOARES, Marilia Vieira. Fundamentos Corporais de Expressão e Movimento. Campinas/SP: UNICAMP, 2003.

FONCILLON, Henri. Vida das Formas. Rio de Janeiro: Zahar Editores, 1983.

CASTILHO, Kathia; MARTINS, Marcelo M. Discursos da Moda: semiótica, design e corpo. São Paulo: Editora Anhembi Morumbi, 2005.

VALÉRY, Paul. Degas Dança e Desenho. São Paulo: Cosac \& Naify, 2003. 